\title{
Effect of time from onset to coming under care on fatality of patients with acute myocardial infarction: effect of resuscitation and thrombolytic treatment
}

\author{
The United Kingdom Heart Attack Study (UKHAS) Collaborative Group
}

\begin{abstract}
Objective-To examine the relation between time from onset of symptoms and coming under ambulance and hospital care on fatality in patients with evolving acute myocardial infarction, and on the proportions who survive because of resuscitation and thrombolytic treatment.

Design-Prospective community and hospital study over two years. Delay was measured from the onset of symptoms to arrival at hospital, and from the onset to coming under care from ambulance personnel.

Setting-Four general hospitals serving three United Kingdom health districts.

Patients-2213 patients under 75 years of age, 111 of whom had been successfully resuscitated from out of hospital cardiac arrest.
\end{abstract}

Interventions-Resuscitation from cardiac arrest; thrombolytic treatment.

Main outcome measures-30 day fatality and lives saved by the two forms of treatment.

Results-Times from symptom onset to coming under hospital care and to starting thrombolytic treatment (given to $53 \%$ of patients) were $\leqslant 1$ hour in $15 \%$ and $2 \%$ of patients respectively, $\leqslant 2$ hours in $54 \%$ and $25 \%$, and $\leqslant 4$ hours in $67 \%$ and $55 \%$. Overall, 30 day fatality was $138 / 1000$ patients treated; $64 / 1000(95 \%$ confidence interval 54 to 74) survived because of treatment, and $80 \%$ of this salvage was attributable to resuscitation. Delay was an important factor: $107 / 1000$ (60 to 144) lives were saved for those coming under care within 1 hour compared with $21 / 1000$ (5 to 37) for those who delayed for more than 12 hours. Further analysis including the 111 patients with out of hospital arrest showed that $34 \%$ of those coming to hospital by ambulance came under ambulance care within 1 hour; for this subset, 30 day fatality was $173 / 1000$, and 136 (109 to 163$)$ lives were saved by treatment.

Conclusions-Results of treatment are strongly related to delay in coming under care. Reduction in delay can reduce mortality from acute myocardial infarction.

(Heart 1998;80:114-120)

Keywords: acute myocardial infarction; fatality; resuscitation; thrombolytic treatment
Delay in coming under medical management for evolving acute myocardial infarction is undesirable because prompt treatment decreases the chance of death from arrhythmia and maximises the potential benefit from thrombolytic treatment. Increasing delay has been correlated with increasing patient age, female sex, and low socioeconomic status..$^{1-3}$ Although patients who may have more severe infarction tend to seek help earlier, ${ }^{45}$ final infarct size $^{67}$ and case fatality ${ }^{8}$ are reduced in those who receive thrombolytic treatment early compared with those who are treated later. However, no quantitative assessment appears to have been made in a large unselected series of patients of the effect of delay on reduction in total fatality by resuscitation and thrombolysis. Data from the United Kingdom heart attack study $^{9}$ have allowed us to examine delay in coming under care as an independent prognostic factor in acute myocardial infarction.

\section{Methods}

Methods have been described elsewhere. ${ }^{9}$ Briefly, between 1 January 1994 and 31 December 1995 we recorded all deaths from acute episodes of ischaemic heart disease and all hospital cases of acute myocardial infarction in people under 75 years of age in the three health districts of Brighton, South Glamorgan, and York. Brighton (population 282 000) is served by one hospital with a coronary care unit, South Glamorgan (population 409 000) has two hospitals, both with coronary care units, while York (269 000) has one hospital with a coronary care unit. Out of hospital deaths were included if they showed ischaemic heart disease as the principal cause of death at coroner's necropsy ( $86 \%$ ) or, in the absence of necropsy (14\%), if death occurred following prolonged chest pain or if patients with a history of ischaemic heart disease died unexpectedly and without any other apparent cause.

Hospital cases of myocardial infarction showed at least two of the following three features: typical or compatible clinical history, sequential electrocardiographic changes, and a rise in serum enzymes to at least twice the upper limit of normal for the hospital laboratory. Patients who died very soon after presentation with prolonged chest pain and one electrocardiogram showing an infarct pattern were also included, as were patients brought in alive after out of hospital cardiac arrest who showed ischaemic changes (ST segment depression, bundle branch block, or old $\mathrm{Q}$ waves) but did 


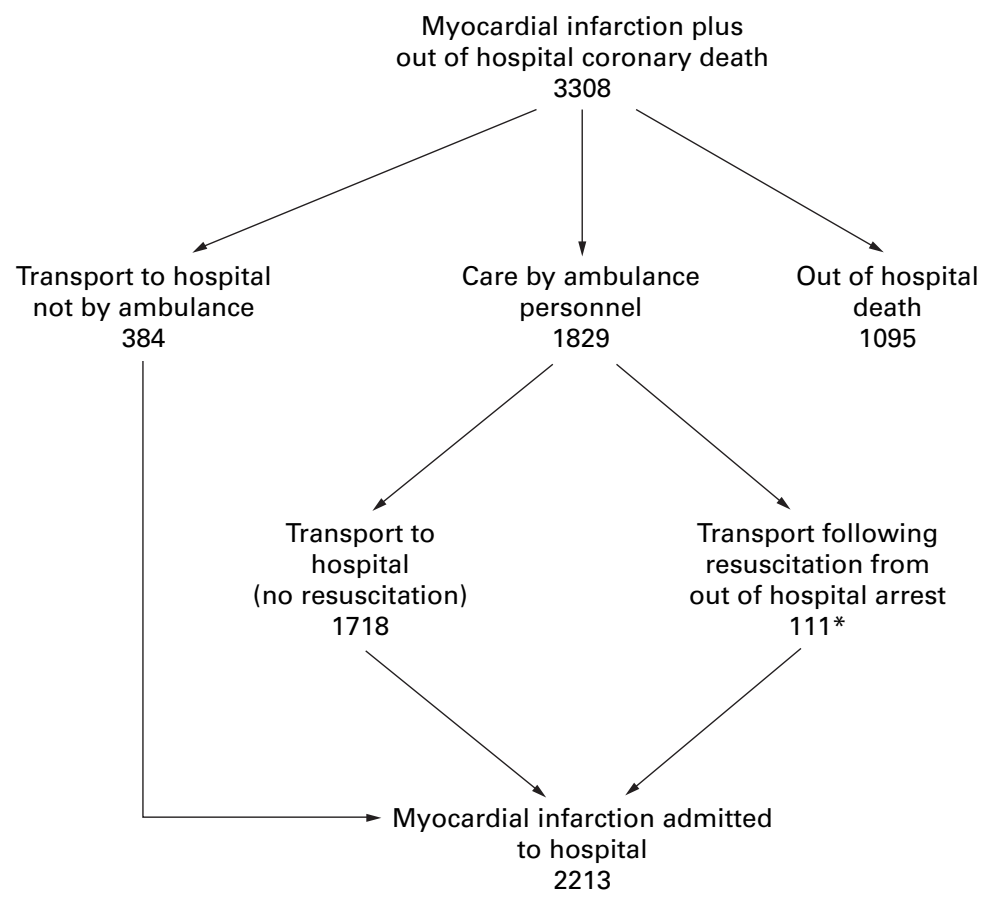

Figure 1 Flow diagram showing out of hospital deaths and the prehospital course of patients admitted to hospital. *Early survivors of 642 attempted resuscitations. ${ }^{9}$

not develop unequivocal evidence of new infarction. Cases were identified from coronary care and accident and emergency department records, by regular visits to medical and surgical wards, and by surveillance of cardiac enzyme results from the hospital laboratories. Lists of patients were checked against discharge diagnoses provided by the hospital information services.

We recorded the prehospital course, times of onset of pain, call to general practitioner and ambulance, and arrival of the ambulance at the patient's home and at the hospital. The onset of infarction was recorded as the time of onset of the most severe chest pain or, in the absence of pain, of the most severe symptom that was compatible with the diagnosis. Details of the hospital course included the diagnostic electrocardiogram, time of administration of thrombolytic treatment, which was given in hospital according to standard indications, ${ }^{10}$ the presence or absence of cardiac failure within 48 hours of admission (clinical evidence of left ventricular failure or interstitial or pulmonary oedema on the chest $x$ ray or both), circumstances of cardiac arrest, success of resuscitation, and 30 day fatality. For patients having multiple cardiac arrests, only the circumstances of the first arrest were recorded. Survi-

Table 1 Delay between onset of symptoms and medical care

\begin{tabular}{|c|c|c|c|}
\hline & $\begin{array}{l}\text { York } \\
(n=746)\end{array}$ & $\begin{array}{l}\text { S Glamorgan } \\
(n=894)\end{array}$ & $\begin{array}{l}\text { Brighton } \\
(n=573)\end{array}$ \\
\hline \multicolumn{4}{|l|}{ Hospital arrival } \\
\hline Median delay (h) & 2.3 & 2.0 & 2.4 \\
\hline Delay $\leqslant 1 \mathrm{~h}(\%)$ & 13 & 22 & 17 \\
\hline \multicolumn{4}{|l|}{ Paramedic care } \\
\hline $\begin{array}{l}\text { Median delay }(\mathrm{h}) \\
\text { Delay } \leqslant 1 \mathrm{~h}(\%)\end{array}$ & 1.9 & 1.6 & 1.9 \\
\hline $\begin{array}{l}\text { Delay } \leqslant 1 \mathrm{~h}(\%) \\
\text { No of } 30 \text { day survivors from out of hospital arrest }\end{array}$ & 29 & 35 & 33 \\
\hline No of 30 day survivors from out of hospital arrest & 18 & 18 & 19 \\
\hline 30 day fatality $(\%)$ & 16 & 15 & 17 \\
\hline
\end{tabular}

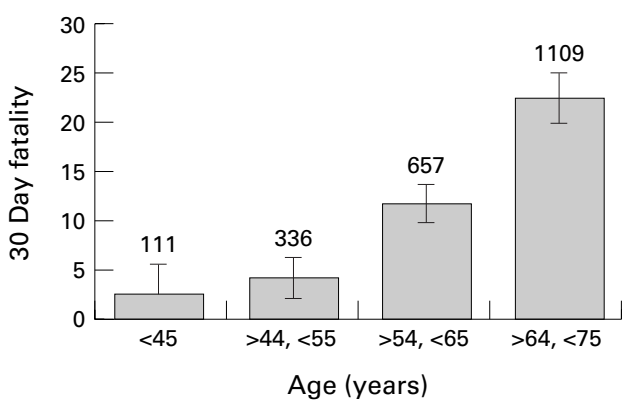

Figure 2 Thirty day fatality rates of all 2213 hospital patients in relation to age, with $95 \%$ confidence intervals. Values above bars refer to the numbers of patients in each age group.

vors from cardiac arrest all had documented ventricular fibrillation, pulseless ventricular tachycardia, or asystole, except for four out of hospital patients who responded to basic life support and were thought to have had an arrest on clinical grounds alone.

We examined the effect of delay in hospital management first by defining delay as the time between onset of symptoms and arrival at hospital and excluding those who had suffered out of hospital arrest. We then performed a second analysis for patients arriving at hospital by ambulance, taking delay as the time between onset of symptoms and coming under ambulance care, and including cases successfully resuscitated from out of hospital arrest. This latter time (usually the time of arrival of the ambulance at the patient's home) was recorded on the form made out by ambulance personnel in $83 \%$ of cases. In the remaining $17 \%$ in which the time was not recorded, we used the hospital arrival times minus 31 minutes. This was used because 31 (SD 17) minutes was the mean time between arrival at home and at the hospital for cases in which this time was known. We restricted the ambulance analysis to patients who reached hospital alive; results in relation to attempts at out of hospital resuscitation are described elsewhere. ${ }^{9}$ In both analyses we divided delay times into five groups of $\leqslant 1$ hour, $>1$ and $\leqslant 2$ hours, $>2$ and $\leqslant 4$ hours, $>4$ and $\leqslant 12$ hours, and $>12$ hours; repeated analyses using differing cut off times yielded comparable results.

Survival was assessed at 30 days after infarction. To estimate the effect of treatment on survival we assumed that all 30 day survivors from cardiac arrest had survived because of resuscitation. The effect of thrombolytic treatment on survival was estimated by application of results of a recent meta-analysis ${ }^{8}$ to the delay between symptom onset and the time at which the thrombolytic drug was actually given. In this analysis it was estimated that the lives of 65 of 1000 patients treated $(95 \%$ confidence interval 38 to 93) were saved by thrombolysis when this was started within one hour of onset of symptoms; numbers saved per 1000 treated respectively at $1-2,2-3,3-6,6-12$, and $12-24$ hours after onset were 37 (20 to 55), 26 (14 to 37), 29 (19 to 40 ), 18 (7 to 29 ) and 9 ( -5 to 22 ). We assumed that the effects of resuscitation and thrombolysis were additive. 
Table 2 Route of admission to hospital and associated delays in 2213 patients with acute myocardial infarction

\begin{tabular}{|c|c|c|c|c|}
\hline & $\begin{array}{l}\text { Call to GP; } \\
\text { transport by } \\
\text { ambulance }\end{array}$ & $\begin{array}{l}\text { Call to GP; transport } \\
\text { not by ambulance }\end{array}$ & $\begin{array}{l}\text { Initial call to } \\
\text { ambulance }\end{array}$ & $\begin{array}{l}\text { Arrival at hospital; } \\
\text { no initial call }\end{array}$ \\
\hline Proportion of cases (\%) & 52 & 10 & 31 & 7 \\
\hline Proportion where times were known (\%) & 91 & 77 & 96 & 89 \\
\hline $\begin{array}{l}\text { Median time }(\mathrm{h}) \text { from onset to arrival at } \\
\text { hospital ( } 25 \text { th and } 75 \text { th centile) }\end{array}$ & $2.6(1.7,5.3)$ & $5.3(2.3,14.9)$ & $1.3(0.9,2.4)$ & $1.7(0.8,3.6)$ \\
\hline
\end{tabular}

Table 3 Baseline factors relating to delay in coming into hospital

\begin{tabular}{lllllc}
\hline & Delay (hours) & & & & \\
\cline { 2 - 6 } & $\leqslant 1$ & $>1, \leqslant 2$ & $>2, \leqslant 4$ & $>4, \leqslant 12$ & $>12$ \\
\hline No of cases (\%) & $309(15)$ & $555(27)$ & $504(25)$ & $387(19)$ & $292(14)$ \\
Age (years) (SD) & $60(10)$ & $62(10)$ & $63(9)$ & $63(9)$ & $63(9)^{\star \star \star}$ \\
Female (\%) & 20 & 26 & 28 & 30 & 27 \\
Cardiac failure within 48 h of admission (\%) & 28 & 30 & 33 & 30 & $38 \dagger$ \\
ST elevation in diagnostic ECG (\%) & 76 & 68 & 62 & 57 & $49^{\star \star \star}$ \\
Thrombolytic treatment (\%) & 70 & 67 & 60 & 48 & $15^{\star \star \star}$ \\
30 day fatality (\%) & 11.7 & 8.8 & 12.7 & 15.2 & $22.6 \dagger$ \\
\hline
\end{tabular}

tp $<0.01 v \leqslant 1 \mathrm{~h} ;{ }^{\star \star \star} \mathrm{p}<0.001$ for trend.

DATA ANALYSIS

Significance levels were assessed by the $\chi^{2}$ test for trend. ${ }^{11}$

\section{Results}

The 2213 patients who were admitted with myocardial infarction were drawn from a total population of 3308 acute coronary events, one third of which had been fatal before admission to hospital. ${ }^{9}$ This is shown in a flow diagram (fig 1), which also shows the role of the ambulance service in resuscitation from out of hospital cardiac arrest and in transport of the patients to hospital.

Among the 2213 patients who were admitted to hospital, 30 day fatality was $15.6 \%$, and it was $13.8 \%$ if 111 patients who had suffered out of hospital arrest were excluded. Survival was strongly related to age (fig 2) and to the presence or absence of heart failure ( $4 \%$ fatality without failure, $\mathrm{n}=1480, v 39 \%$ fatality with failure, $\mathrm{n}=732 ; \mathrm{p}<0.001)$.

Of the $83 \%$ of patients who arrived at hospital by ambulance, approximately two thirds had consulted their general practitioner before the ambulance arrived and one third had telephoned the ambulance directly. Of the $17 \%$ who arrived by other means of transport, a little over one half had consulted their practitioner. The median time to coming under ambulance care was 1.8 hours and for arrival at hospital, 2.3 hours. Neither the times nor the 30 day fatality rates differed significantly among the centres (table 1).
DELAY IN RELATION TO ROUTE OF ADMISSION TO HOSPITAL

Table 2 shows the median times, with 25 th and 75 th centile values, from onset of symptoms to coming under care for the four groups of patients: those who called their general practitioner and arrived at hospital by ambulance, those who called their practitioner and arrived by other means, those who called the ambulance directly, and those who arrived without calling their doctor or an ambulance. The median delay for patients who called the ambulance without reference to their practitioner was 1.3 hours less than for those who called their practitioner and arrived by ambulance. It appeared that the difference was accounted for mainly by a shorter delay in calling for help for patients who telephoned the ambulance directly (data not shown), but this is uncertain because times of calls to the general practitioner were unknown in nearly half of the cases.

EFFECT OF TIME FROM ONSET TO HOSPITAL ARRIVAL FOR PATIENTS WHO DID NOT HAVE AN OUT OF HOSPITAL ARREST

Of the 2102 patients who arrived at hospital without having suffered out of hospital arrest, times from onset to arrival were known with sufficient accuracy for categorisation into one of our five groups in 2047 (97\%). Numbers in each group and their baseline characteristics are shown in table 3. Fifteen per cent of the patients arrived at hospital within one hour and

Table 4 Proportion of patients with cardiac arrest in hospital, attempts at resuscitation, and rhythm recorded, according to delay in presentation

\begin{tabular}{lccccc}
\hline & Delay (hours) $\dagger$ & & & \\
\cline { 2 - 5 } & $\leqslant 1$ & $>1, \leqslant 2$ & $>2, \leqslant 4$ & $>4, \leqslant 12$ & $>12$ \\
\hline $\begin{array}{l}\text { No of cases } \\
\text { No (\%) with first cardiac arrest in hospital }\end{array}$ & 309 & 555 & 504 & 387 & 292 \\
$\begin{array}{l}\text { Median time (h) of first cardiac arrect after onset of } \\
\text { symptoms }\end{array}$ & $57(18)$ & $74(13)$ & $86(17)$ & $64(17)$ & $68(23)$ \\
$\begin{array}{l}\text { No (\%) of patients with arrest where resuscitation } \\
\text { attempted }\end{array}$ & 4.4 & 6.3 & 18.2 & 25.3 & $55.5^{\star \star \star}$ \\
$\begin{array}{l}\text { No (\%) of resuscitation attempts where VF was the first } \\
\text { rhythm recorded }\end{array}$ & $47(82)$ & $58(78)$ & $57(66)$ & $44(69)$ & $43(63)^{\star \star}$ \\
\begin{tabular}{l} 
No (\%) of 30 day survivors of resuscitation \\
\hline
\end{tabular} & $31(66)$ & $41(71)$ & $33(58)$ & $19(43)$ & $22(51)^{\star \star}$ \\
$8(21)$ & $6(14)^{\star \star \star}$ \\
\hline
\end{tabular}

${ }^{\star \star}{ }_{\mathrm{p}}<0.01,{ }^{\star \star \star} \mathrm{p}<0.001$ for trend.

†Delay times unknown for 18 arrest and three survivors.

$\mathrm{VF}$, ventricular fibrillation. 
Table 5 Use and success of thrombolysis in 1090 patients in relation to delay from onset to administration

\begin{tabular}{lccccc}
\hline \multicolumn{5}{c}{ Delay (hours) $t$} \\
\cline { 2 - 6 } & $\leqslant 1$ & $>1, \leqslant 2$ & $>2, \leqslant 4$ & $>4, \leqslant 12$ & $>12$ \\
\hline No (\%) of patients treated & $21(2)$ & $240(22)$ & $440(40)$ & $346(32)$ & $43(4)$ \\
30 day fatality (\%) & 0 & 5 & 10 & 13 & $23^{\star \star \star}$ \\
\hline$\star \star \star \mathrm{p}<0.001$ for trend. & & & & & \\
$\dagger$ Times known in 96\% of patients. & & & &
\end{tabular}

$42 \%$ within two hours. Increasing delay was associated with a slight increase in age and a progressive decline in the proportion of patients who showed ST segment elevation in their diagnostic electrocardiogram and who were given thrombolytic treatment. Cardiac failure within 48 hours of admission occurred with similar frequency in the groups who delayed for less than 12 hours, but was more common among patients who delayed for more than 12 hours $(<0.01)$. Case fatality did not differ significantly for delays of up to 12 hours, but it was higher $(p<0.01)$ for patients who delayed for more than 12 hours. However, significantly more lives were saved by treatment for patients arriving early than for those with a longer time between symptom onset and coming under care (see later).

Cardiac arrest and resuscitation in hospital Cardiac arrest occurred in 367 patients (table 4). Resuscitation was attempted in $263(72 \%)$ but was not attempted in the remaining $28 \%$ because of severe heart failure or comorbidity. Of the 263 patients in whom resuscitation was attempted, 97 (37\%) survived for 30 days; for the $57 \%$ of patients in whom ventricular fibrillation or pulseless ventricular tachycardia were the first rhythm recorded, 30 day survival was $58 \%$, but it was only $8 \%$ for the $43 \%$ of cases in which some other rhythm was recorded.

Table 4 shows a marked increase in the median time from onset of symptoms to hospital cardiac arrest as time from onset to presentation lengthened. Resuscitation was attempted

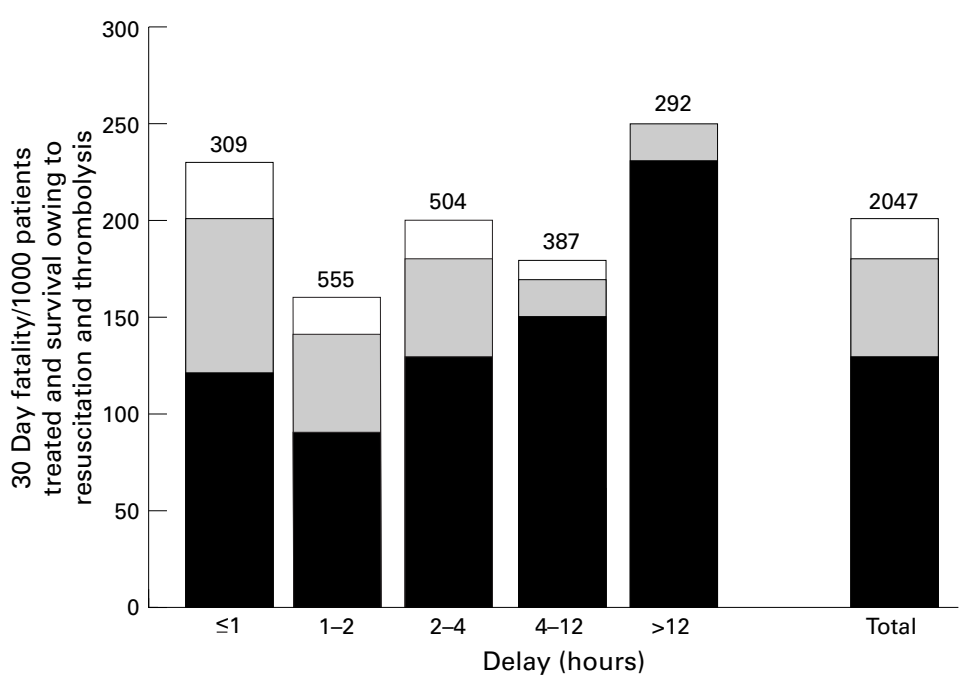

Figure 3 Thirty day fatality (black bars), lives saved by resuscitation from in-hospital cardiac arrest (shaded bars), and estimated to have been saved by thrombolytic treatment (white bars) according to delay in presentation to the hospital. Numbers above the bars are the numbers of patients in each group. more frequently in the earliest presenting patients, it was more likely to have been successful, and ventricular fibrillation was more likely to have been the presenting rhythm.

\section{Thrombolytic treatment}

Fifty four per cent of the patients received thrombolytic treatment and times were known in $96 \%$ of these $(n=1090)$. Subsequent audit showed that omission of treatment could be attributed to therapeutic error in approximately $25 \%$ of patients who did not receive it. In the remainder, omission was justified on clinical grounds. Streptokinase was the drug used in $83 \%$ of cases. The median hospital delay in starting treatment (door to needle time) was 50 minutes, but the median "onset to needle" time was nearly four times greater, at 185 minutes. Table 5 shows the numbers of patients treated within the periods from onset to receiving treatment, together with the respective fatality rates. Whereas the proportion of patients coming under care within one and two hours were $15 \%$ and $42 \%$ respectively, and more than two thirds presenting within two hours eventually received thrombolytic treatment, proportions who received thrombolysis within one or two hours were only $2 \%$ and $24 \%$. However, fatality was significantly lower for patients who were treated within two hours of the onset than for those who were treated later (table 5).

Effect of admission delay on success of treatment Figure 3 shows case fatality, together with the proportions of lives saved by resuscitation or estimated to have been saved by thrombolytic treatment according to time from onset to coming under hospital care. In absolute terms 107 (72 to 141) lives were saved by hospital treatment that started within one hour of onset, and about $70 \%$ of this salvage was the result of resuscitation. After one hour the salvage declined, so that for delays of more than 12 hours only 21 (5 to 36 ) lives were saved, and this was solely because of resuscitation. This time trend was highly significant $(p<0.001)$, both comparing numbers of deaths with lives known (by resuscitation) and estimated (by thrombolytic treatment) to have been saved, and when the analysis was restricted to those in whom survival was known to have been due to resuscitation. Numbers of lives saved/1000 patients treated, with their $95 \%$ confidence intervals, are shown in fig 4 .

EFFECT OF TIME FROM ONSET TO COMING UNDER AMBULANCE CARE FOR PATIENTS ARRIVING ALIVE AT HOSPITAL, INCLUDING THOSE WITH OUT OF HOSPITAL CARDIAC ARREST

Eighty three per cent of the 2213 patients arrived at hospital by ambulance. All ambulances had two man crews, all carried defibrillators, and in the great majority of cases at least one member of the crew had a paramedic qualification, which included training in endotracheal intubation and administration of cardioactive drugs. Of the 111 patients who had been successfully resuscitated by paramedics before reaching hospital, 55 (50\%) were 30 
Table 6 Baseline factors, 30 day fatality, and survival owing to treatment in relation to time from onset of symptoms to coming under ambulance care

\begin{tabular}{llll}
\hline & Delay (hours) & & $>2, \leqslant 4$ \\
\cline { 2 - 4 } & $\leqslant 1$ & $>1, \leqslant 2$ & $324(18)$ \\
\hline No of cases (\%) & $612(34)$ & $401(22)$ & $63(9)$ \\
Age (years) (SD) & $62(10)$ & $63(9)$ & 29 \\
Female (\%) & 23 & 29 & 1 \\
Out of hospital arrest (\%) & 14 & 3 & 133 \\
30 day fatality/1000 & 173 & $99(70$ to 128$)$ & $64(34$ to 100$)$ \\
Survival owing to treatment/1000 (95\% CI) & $136(109$ to 163$)$ & & \\
\hline
\end{tabular}

CI, confidence interval.

day survivors. Ventricular fibrillation or pulseless ventricular tachycardia had been recorded in $74 \%$ of cases. In 85 of the 111 patients, premonitory symptoms were presumed to have been absent or had been present for less than one hour, in 13 they had been present for one to two hours, in two for two to four hours, and in 11 for more than four hours.

Of the 1829 patients arriving by ambulance, times from onset to coming under care were known or could be estimated in 1791 (98\%). Table 6 shows patient characteristics for delay times of up to four hours: after four hours data were similar to those shown in table 3 . Also shown in table 6 are the 30 day case fatality rates and the salvage (with $95 \%$ confidence intervals)/1000 patients treated. These latter figures were the sums of successful resuscitations (prehospital and hospital) and the estimated benefit from thrombolysis given in hospital. More than twice the proportion of patients $(34 \%)$ came under ambulance care within one hour as the proportion who came under hospital care (15\%). Baseline characteristics were similar to those for delay in hospital admission (table 3), but fatality rates were higher because of inclusion of patients who had been resuscitated from out of hospital arrest.

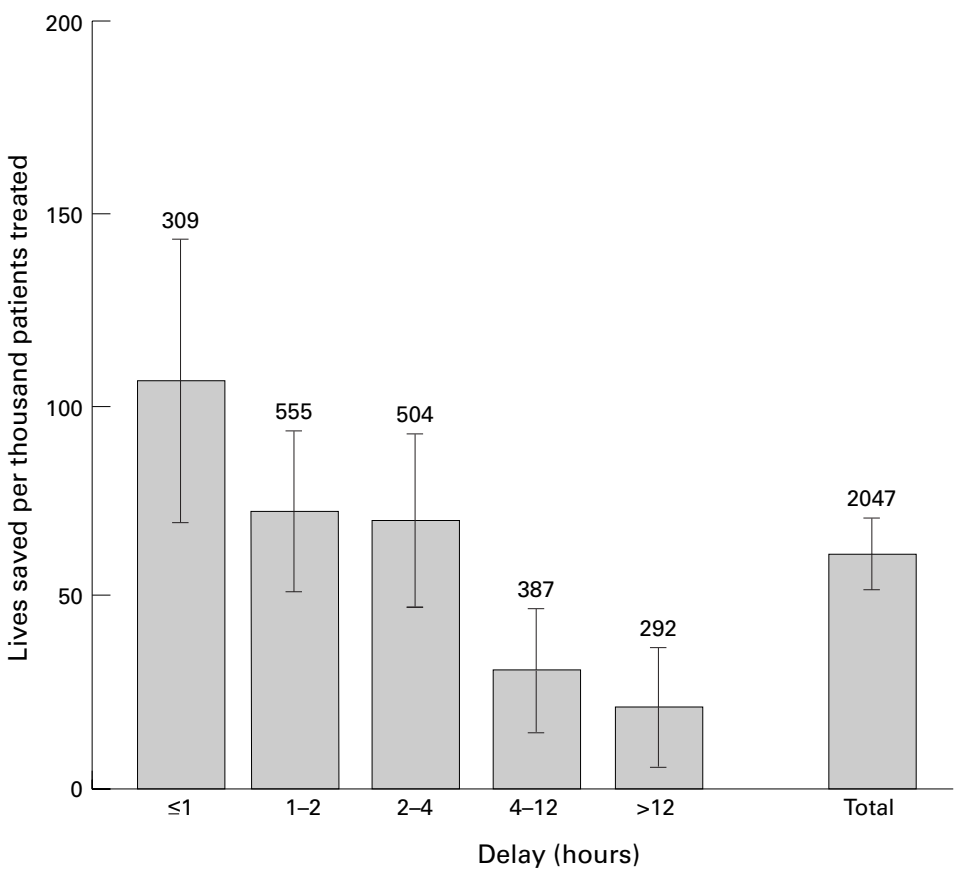

Figure 4 Survival owing to in-hospital resuscitation and thrombolytic treatment, with $95 \%$ confidence limits of the estimates, according to delay in presentation to the hospital. Numbers above bars are the numbers of patients in each group.

\section{Discussion}

Although reduction in delay has long been recognised as a key to success in the treatment of acute myocardial infarction, delay is particularly difficult to measure, not only because of unreliability of patients' memories of the time of onset but also because of uncertainty about when infarction starts, particularly when symptoms are atypical or the onset is gradual or stuttering. Thus measurement is at best an approximation and is almost certainly an overestimate in view of experimental evidence that infarction does not start until 20 to 30 minutes after coronary occlusion and electrocardiographic changes. Moreover patients who delay longer do not necessarily have the same prognosis at the onset as those who do not delay. In particular, patients who call early have been shown to have more severe infarcts than those who call later. ${ }^{4}$ Patients who delay for more than 12 hours are also a high risk group, consisting largely of those with an atypical presentation who are sent to hospital because of a complication, usually heart failure. Thus the curve of case fatality versus delay tends to be $\mathrm{U}$ shaped, ${ }^{12}$ with higher fatalities in patients who present very early and very late. Our results support this. Nevertheless, apart from a higher incidence of cardiac failure in patients who delayed for more than 12 hours, the differences in baseline characteristics according to delay in our series (table 3 ) were less than might have been expected.

In addition to the difficulties in definitions of the onset of infarction, there is also difficulty in defining the start of treatment. Of 15230 day survivors of cardiac arrest in the present series, more than one third owed their lives to resuscitation from out of hospital arrest by highly trained ambulance personnel. For this reason we defined time from onset to coming under care in two ways - by the time of arrival at hospital and by the time of coming under paramedic ambulance care, the two analyses respectively excluding and including the patients with out of hospital arrest. Owing to the accuracy of the ambulance records, times of coming under care were much more reliable than the patients' memory of the time of onset of symptoms. For patients admitted to hospital, however, definition of delay in coming under paramedic ambulance care ignores cases in which resuscitation was attempted outside hospital but was unsuccessful, the patient not surviving to reach hospital. As shown in fig 1, and more fully described elsewhere, ${ }^{9}$ these 
patients were survivors of a much larger cohort, one third of whom had died before they could reach hospital.

Except in patients who delayed for more than 12 hours, we did not show any significant effect of delay on 30 day survival. Had it not been for treatment, however, fatality for patients coming under care within one or two hours would have been nearly double what actually occurred. Our results show that benefits from the "golden hour" related much more to resuscitation than to thrombolysis. Indeed, because of delays associated with administration of thrombolytic drugs in hospital, only 22 patients ( $2 \%$ of those eligible) received thrombolysis within one hour, although $253(25 \%)$ received it within two hours (table 5). Our estimate of the benefits from thrombolysis were based on fatality rates for delays shown by the meta-analysis, ${ }^{8}$ and because so few patients were treated within one hour of onset they show only minimal additional benefit for those who came under care within this time. However, it is of interest that the fatality we actually found when thrombolysis was given within two hours (table 5) was half or less of the fatality when treatment was given later. The thrombolytic trials on which the meta-analyses are based ${ }^{813}$ measured delay from onset to randomisation for treatment; the time to administration of the drug must inevitably have been longer than this. Moreover, results from trials of thrombolytic treatment given outside hospital ${ }^{1415}$ suggest that the period of optimum benefit may extend beyond one hour. Thus we may have underestimated the benefit of thrombolysis for patients who were seen within the first hour, but did not receive treatment until the second. However the $95 \%$ confidence limits of 30 day fatality for the relatively small number (261) of patients who were treated within two hours are too wide to allow us to make any predictions on possible benefits that might have accrued had patients been treated with thrombolysis at the time that they first came under care.

Our finding that approximately four times as many lives were saved by resuscitation as by thrombolytic treatment depends on the assumption that the effects of these two forms of treatment were additive, and that reperfusion was not the cause of ventricular fibrillation in a significant number of cases. There is experimental evidence that reperfusion causes ventricular fibrillation, and a significant excess $(2.5 \% v 1.6 \%, \mathrm{p}<0.02)$ of out of hospital fibrillation was seen among patients in the European myocardial infarction project ${ }^{16}$ who received anistreplase prehospital compared with those who received it after arrival at hospital. However, this was balanced by an excess of in-hospital fibrillation among those who received a placebo injection outside hospital and anistreplase after arrival. We cannot exclude the possibility that reperfusion was the cause of some cardiac arrests in our study, but scrutiny of the time that ventricular fibrillation occurred in relation to the start of drug infusion showed that rather more arrests occurred before infusion was started than during the two hours afterwards.

Cardiac arrest occurred later and success of resuscitation diminished as time to presentation lengthened (table 4). Late cardiac arrest is a complication of large infarctions and it is likely that many of our late presenting infarcts were large because thrombolysis had not been given or had been delayed. Had all 288 patients who presented after 12 hours presented within two hours, and had indications for thrombolysis been the same as in those who presented earlier, an additional 20 to 30 lives might have been saved, corresponding to a further reduction in fatality of $1-2 \%$.

In conclusion, despite difficulties of measurement and definition, reduction in delay offers important opportunities for improvement in the treatment of acute myocardial infarction. The public should be educated on the symptoms of impending myocardial infarction and should be advised to ring the emergency services first rather than contacting their general practitioner. ${ }^{17}$ Systematic recording of delay times in patients admitted to hospital should provide a valuable audit method for assessing improvements in response by patients and in the standard of treatment, both by the ambulance service and by the hospital. Our data from contemporary routine practice in general hospitals provide further support for strategies to minimise delay to care for patients with acute myocardial infarction.

The UKHAS was supported by audit funds from the Department of Health and by the PPP Medical Trust (RMN).

Participating centres

Brighton (coordinating centre, Cardiac Department, Royal Sussex County Hospital): $\mathrm{R} M$ Norris (honorary consultant cardiologist, study director), Gaynor Dixon (research sister responsible for coordination and database management), P S Wong (research registrar), Nina Morris (research sister), Maria Workman and Janet Stevens (secretaries).

Cardiff (Department of Cardiology, University Hospital of Wales): W J Penny (consultant cardiologist), Nadia El Gaylani (research registrar), Anne Thomas (research sister), Lesley Davies (research sister)

York (Department of Cardiology, York District Hospital): R $M$ Boyle (consultant cardiologist), Kathryn Griffith (research registrar), Siân Wiseman (research sister), Sue Cooper (research sister).

Steering committee

R Vincent (Brighton, Chairman), R M Boyle (York), D A Chamberlain (Brighton), D G Julian (London), R M Norris (Brighton), W J Penny (Cardiff), C F M Weston (Swansea).

Publications committee

R M Norris, D G Julian, C F M Weston.

Statistical adviser

D R Robinson (School of Mathematical Sciences, University of Sussex).

1 Schmidt SB, Borsch MA. The prehospital phase of acute myocardial infarction in the era of thrombolysis. Am f Cardiol 1990;65:1411-15.

2 Ghali JK, Cooper RS, Kowatly I, et al. Delay between onset

2 Ghali JK, Cooper RS, Kowatly I, et al. Delay between onset
of chest pain and arrival to the coronary care unit among of chest pain and arrival to the coronary care unit among minority and disa

3 Yarzebski J, Goldberg RJ, Gore JM, et al. Temporal trends and factors associated with extent of delay to hospital arrival in patients with acute myocardial infarction: the Worcester heart attack study. Am Heart f 1994;128:255-63.

4 Rawles JM, Metcalfe MJ, Shirreffo C, et al. Association of patient delay with symptoms, cardiac enzymes, and outcomes in acute myocardial infarction. Eur Heart f 1990; 11:643-8.

5 Trent RJ, Rose EL, Adams JN, et al. Delay between the onset of symptoms of acute myocardial infarction and seeking medical assistance is influenced by left ventricular function at presentation. Br Heart $\mathcal{F}$ 1995; 73:125-8.

6 Hermens WT, Willems GM, Nijssen KM, et al. Effect of Hermens WT, Willems GM, Nijssen KM, et al. Effect of
thrombolytic treatment delay on myocardial infarct size. thrombolytic treatmen
Lancet 1992;340:1297.

7 Raitt MH, Maynard C, Wagner GS, et al. Relation between symptom duration before thrombolytic therapy and final myocardial infarct size. Circulation 1996;93:48-53. 
8 Boersma E, Maas ACP, Simoons ML. Early thrombolytic treatment in acute myocardial infarction: reappraisal of the Golden Hour. Lancet 1996:348:771-5.

9 Norris RM, on behalf of the UK Heart Attack Study Investigators. Fatality outside hospital from acute coronary events in three British health districts 1994-95. BMF 1998; 316:1065-70.

10 Task force on the management of acute myocardial infarction of the European Society of Cardiology. Acute myocardial infarction: pre-hospital and in-hospital management. Eur Heart $\mathcal{F}$ 1996;17:43-63.

11 Altman DG. Practical statistics for medical research. London: Chapman and Hall, 1991:263.

12 Rawles JM, Haites NE. Patient and general practitioner delays in acute myocardial infarction. BMF 1988;296;882-4.

13 Fibrinolytic Therapy Triallists Collaborative Group. Indications for fibrinolytic therapy in suspected acute myocardial infarction: collaborative overview of early mortality and major morbidity results from all randomised trials of more than 1000 patients. Lancet 1994;343:311-22.

14 Weaver WD, Cerquiera M, Hallstrom AP, et al. Pre-hospital initiated vs hospital initiated thrombolytic therapy. $\mathscr{f} A M A$ 1993;270:1211-16.

15 Rawles J. Magnitude of benefit from earlier thrombolytic treatment in acute myocardial infarction: new evidence from Grampian region early anistreplase trial (GREAT). from Grampian region

16 European Myocardial Infarction Group. Prehospital thrombolytic therapy in patients with suspected acute myocardial infarction. N Engl F Med 1993;329:383-5.

17 Dixon GF, Norris RM, Vincent R. Heart Attack Action! A campaign to increase community knowledge. Heart 1996; 76:P80.

\section{STAMPS IN CARDIOLOGY}

\section{Heparin}

The joint theme for all European postal administrations in 1994 was inventions and discoveries. The two Europa stamps issued for this by Aland depict medical discoveries connected with the Åland Islands. The first stamp featured von Willebrand's disease and its genetic linkage. The disease was common in Aland as the islands are quite isolated and intermarriages common. EA von Willebrand was head of the department of internal medicine at the Deaconess Hospital in Helsinki, and studied the disease in two large families in the Aland archipelago. The second stamp in the series commemorates the purification of heparin by Erik Jorpes and shows the antithrombin binding pentasaccharide sequence in the heparin molecule. The stamps were designed by Kurt Simons, an illustrator and designer from Bromma, Sweden. The first day of issue was 5 May 1994. Five hundred thousand of each denomination were printed in sheets of 40 and printed in four colour offset. The First Day Cover and special cancellation mark depicting drugs, medicine, and academic skills were also designed by the same artist.

The discovery of heparin in 1916 resulted from the persistence and careful research of a preclinical medical student, Jay McLean, then aged 26. McLean was an orphan and had to work for three years in labouring jobs to save enough money to fulfill his ambition of entering Johns Hopkins medical school. Once accepted, and even though his aim was academic surgery, he asked to spend his first year in physiology where Dr William H Howell gave him the task of isolating a clotting factor from brain tissue. McLean achieved this and then, on his own, studied a liver extract. This also had a clotting factor but crucially McClean went on testing it for several weeks. $\mathrm{He}$ found that the thromboplastic action disappeared, and that a powerful anticoagulant factor was now present - this was heparin. Howell made a crude preparation of it, which led Charles Best in Toronto to work on the problem. His colleagues at the Connaught

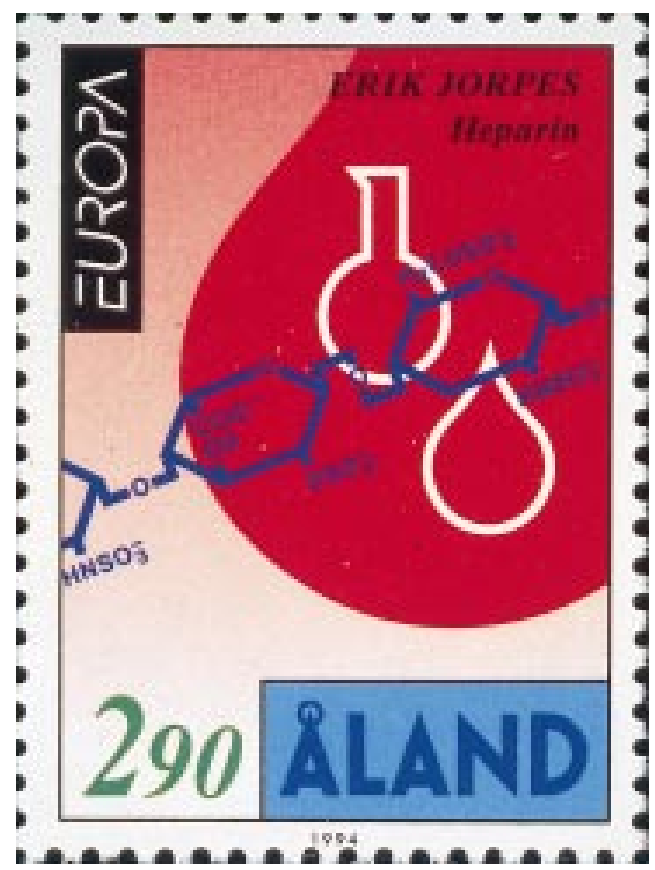

Laboratories, Arthur Charles and David Scott, found that beef lung was the best source and in 1935 Best and a surgeon, Gordon Murray, did clinical trials with that material.

A Swedish chemist, Erik Jorpes (born on Kökar, Åland in 1894), then did fine work on the chemistry of the Toronto heparin, which was in fact different from that found by McClean and Howell, and he identified it as an acidic sulphated polysaccharide. Also in Sweden the pioneer cardiac surgeon, Clarence Craaford, had already operated with success on two patients with massive pulmonary embolism. Using material supplied by Jorpes he initiated a research programme in 1935 of using heparin to prevent postoperative thrombosis and embolism. 